Gustatory hallucinations elicited by a careful history may be helpful in the cortical localization of the seizure discharge. In my experience, this manifestation of temporal lobe seizures is rare in children but nonetheless important to consider.

\title{
DYSLEXIA, AND LEARNING DIFFICULTIES
}

PERIPHERAL VISION IN DYSLEXICS

Scientists from the Research Laboratory of Electronics and the Departments of Biology, Electrical Engineering, and Computer Science at M.I.T. Cambridge, Mass. have collaborated in an investigation of the peripheral and foveal (central) vision of 5 dyslexic adult subjects compared to 5 normal readers. Two letters, one at the fixation point and one in the periphery, at varying distances apart feccentricities', wers prescnted cimultuncously ar.d the scorcs for the correct identification of the single peripheral letters in the two groups were compared.

At $2.5^{\circ}$ eccentricity (near central fixation point) the scores of normal readers were the higher. Correct identification fell off with increasing eccentricity ( 2.5 to 12.5 degrees) in both groups but the fall off was slower in severe dyslexics than in normal readers. At $7.5^{\circ}$ eccentricity (peripheral field vision), the scores of dyslexic subjects were higher than those of normal readers; i.e. they were better at perceiving briefly presented letters in the periphery.

When a string of three letters was substituted for the single letters in the periphery, the severe dyslexic could identify none of the letters at $2.5^{\circ}$ eccentricity (near central vision) but at $5^{\circ}$ and beyond (peripheral vision) his identification of letters was near normal. After a program of exercises involving spatial organization and eye-hand co-ordination and the use of a simple device to utilize his optimal peripheral vision in reading, the performance of the severe dyslexic subject showed improvement after 4 months up to a 10th grade level. (Geiger G, Lettvin JY. N Engl J Med 1987;316:1238).

COMMENT: These interesting findings and suggested treatments will undoubtedly bring joy to the optometrists and those who favor the Kephart and Frostig methods in the management of dyslexia. Kephart's three-crucial perceptual skills to be mastered as prerequisites to reading are form perception, spatial discrimination, and ocular control. If these skills are underdeveloped, according to Kephart, the child will develop faulty intersensory integration abilities and concept formation. Frostig, similarly, maintains that adequate perceptual functioning in young children is the foundation on which later school success depends. Critics of these methods state that evidence from research studies does not support their value in reading remediation. However, several authors have emphasized abnormalities of eye movements, tracking, and visual fixations as a characteristic of dyslexics and further studies are needed.

The authors, Geiger and Lettvin, conclude that in dyslexics, there is an interaction between foveal and peripheral vision that degrades the normal ability to read in the foveal field. Dyslexics have masking or suppression of letter discrimination in the central foveal field and better than normal peripheral visual identification of letters. They suggest that dyslexics should be taught to read by use of their peripheral vision. Neurologists might argue alternative explanations for the findings based on changes in attention or 
cortical visual organization but the study offers a simple and practical method of treatment that is worthy of trial in a larger number of younger subjects. The results could be different in children from those in adults, aged $18-25$, used in this study (See PED NEUR BRIEFS $\underline{1}(1): 5$ )

\section{TRICYCLIC ANTIDEPRESSANTS AND ATTENTION DEFICIT DISORDER}

A review of the literature concerning imipramine and other tricyclics in the treatment of attention deficit disorder (ADD) is presented from the Dept Psychiatry, Univ. Texas Health Sci Cntr, 7703 Floyd Carl Drive, San Antonio, TX 78284. Imipramine was the drug of choice in a subgroup of children with ADD who had higher levels of anxiety or depression or both. Methylphenidate was superior to imipramine in the treatment of ADD overall.

The author conciudes that: (i) reports of imipramine as the arug of choice in ADD are unjustified, (2) stimulants are the first choice and imipramine second, (3) children with ADD complicated by anxiety and/or mood disturbance may respond better to imipramine than to methylphenidate, (4) doses of imipramine are not superior to higher doses and $<\mathrm{lmg} / \mathrm{kg} /$ day is ineffective. (Pliszka SR. J Amer Acad Child Adol Psychiat, 1987; 26:127-132).

COMMENT: My own experience, without the benefit of double-blind controls, would place methylphenidate as the drug of choice in ADD with hyperactivity uncomplicated by anxiety. As a pediatric neurologist, I am reluctant to prescribe imipramine for ADD with anxiety or depression (1) because of the dangers of cardiac arrhythmia with accidental poisoning and (2) my inability to evaluate properly its effects on the associated psychiatric symptoms. It is my opinion that this treatment should be followed by our colleagues in child psychiatry. Since imipramine has fallen out of favor in the treatment of nocturnal enuresis which sometimes complicates ADD, I no longer use the drug in my practice. For those patients with ADD and secondary anxiety reactions, I prefer thioridazine (Mellaril) if medication is required.

Drugs in the management of ADD with hyperactivity are controversial and they play a larger role in the USA than in England, whore dictary modification is in voguc. With incrcascd awurcnces of the problem by educators and more individualized attention to associated learning disabilities, the need for medication has lessened appreciably. Behaviour modification and other psychological approaches to deal with hyperactivity are often sufficient to deal with anxiety caused by frustration and to lessen the impulsivity.

The present article emphasizes the need to correctly classify children with ADD into groups with or without conduct and anxiety disorders when evaluating drug effects. Werry JS et al, writing in the same journal, find that the co-existence of $A D D$ and conduct disorder increases the degree of disability and suggest that ADD with hyperactivity is a cognitive disorder, possibly of neurodevelopmental origin. ( $\underline{\mathrm{J}}$ Amer Acad Child Adol Psychiat. 1987; 26:133-143). 